\title{
Efeitos do treinamento moderado contínuo sobre parâmetros imunológico e metabólico de ratos suplementados com maltodextrina
}

\author{
Cátia Fernandes LEITE* \\ Marta Gonçalves AMARAL* \\ Claudia Pinho HARTLEBEN* \\ Carolina Borges HAX* \\ Airton J osé ROMBALDI*
}

*Universidade Federal de Pelotas.

\section{Resumo}

0 objetivo deste estudo foi verificar os efeitos do exercício moderado contínuo sobre a contagem total e diferencial de leucócitos, as concentrações de glicose sérica e os teores lipídicos de ratos suplementados e não suplementados com solução carboidratada. Para tanto, 35 ratos Wistar, machos foram distribuídos em quatro grupos: sedentários não suplementado $(n=10)$ e suplementado $(n=8)$; treinados em exercício aeróbio moderado contínuo não suplementado $(n=9)$ e suplementado $(n=8)$. 0 período de treinamento foi de seis semanas de natação em padrão contínuo com sobrecarga correspondente a 3\% do peso corporal. Durante cinco dias os animais foram suplementados com uma dose diária de 0,48 g. $\mathrm{kg}^{-1}$ de maltodextrina dissolvida em água ou receberam água pura. 0 exercício moderado causou uma diminuição significativa na glicemia $(p<0,001)$ e no número de linfócitos sanguíneos $(p<0,01)$, entretanto, a maltodextrina proporcionou um aumento significativo nos linfócitos dos animais treinados ( $p$ $<0,03)$. Não houve efeito do treinamento e da maltodextrina no perfil lipídico. Conclui-se que com seis semanas de treinamento foi possivel causar queda no número de linfócitos e concentração de glicose sérica, mas com cinco dias de suplementação o declínio na contagem de linfócitos foi atenuado sem, no entanto, causar elevações no perfil lipídico.

UnITERMOS: Capacidade aeróbia; Glicemia; Linfócitos; Carboidrato.

\section{Introdução}

O treinamento físico pode modular várias funções do sistema imunológico (MURPHY, DAVIS, BROwn, Carmichael, Carson, Van Rooijen, Ghaffar \& MAYER, 2008). O exercício de alta intensidade ou de duração prolongada pode produzir uma janela aberta indicativa de um maior risco de infecções (Radak, Chung, Koltai, TaYlor \& Goto, 2008). Além disso, o exercício de alta intensidade causa danos aos tecidos, produção de hormônios do estresse e alteração na quantidade circulante e na função de várias células do sistema imune (NATALE, BRENNER, Moldoveanu, Vasiliou, SHek \& SHePhard, 2003). A hipoglicemia ocasionada durante o exercício também resulta em elevada resposta ao estresse e uma associada imunossupressão (Close, Ashton, CABLE, Doran, Noyes, McArdle \& Maclaren, 2005).

Períodos prolongados de exercício físico podem causar depressão temporária em diversos aspectos da função imunológica, contudo, em intensidade e volume moderados de treinamento ocorrem as melhores respostas imunes, comparados a intensidades baixas e elevadas (Araújo, Gobatto, Hirata, Hirata, CaVaglieri \& Verlengia, 2008). O treinamento moderado, também pode reduzir o risco de doença cardiovascular promovendo saúde (WOLACH, GAvrieli, Ben-Dror, Zigel, Eliakim \& Falk, 2005).

Para maximizar os efeitos do treinamento moderado sobre a função imune, Cox, Pyne, Cox, CALlister 
e GLeESON (2008) salientam que o consumo de carboidratos antes e/ou durante o exercício exerce uma maior magnitude na resposta das citocinas ao exercício físico. Gleeson, Nieman e Pedersen (2004) recomendam o consumo de uma solução carboidratada durante o treinamento para atenuar alguns dos efeitos imunossupressivos do exercício prolongado.

A falta de consenso na literatura sobre qual o tipo de carboidrato e concentração da solução que ocasionaria efeitos positivos sobre células imunológicas; além de

\section{Materiais e métodos}

\section{Grupos experimentais}

Foram utilizados 35 ratos machos da linhagem Wistar com 60 dias e pesando no início do experimento 304,8 a 409,4 gramas. Os animais provenientes do Biotério da Universidade Federal de Pelotas (UFPel) foram alimentados com ração balanceada padrão $(\mathrm{Nu}-$ vilab ${ }^{\circledR} \mathrm{CR} 1$ ), água “ad libitum” e distribuídos em gaiolas coletivas. A temperatura ambiente foi controlada entre $21-25^{\circ} \mathrm{C}$ e fotoperíodo de $12 \mathrm{~h}$ claro e $12 \mathrm{~h}$ escuro.

Os animais foram transferidos para o Laboratório de Bioquímica e Fisiologia do Exercício da UFPel (LABFex/UFPel), pesados e distribuídos, aleatoriamente, em quatro grupos: sedentários não suplementados (sed $\mathrm{n}$ sup, $\mathrm{n}=10$ ) e suplementados (sed sup, $\mathrm{n}=8$ ); treinados em exercício aeróbio contínuo de intensidade moderada não suplementados (aer $\mathrm{n}$ sup, $\mathrm{n}=9$ ) e suplementados (aer sup, $\mathrm{n}=8$ ).

\section{Protocolo de treinamento}

O período de treinamento foi de seis semanas, sendo a primeira de adaptação ao meio líquido (cinco vezes por semana) com sobrecargas progressivas e em tanque coletivo, cilíndrico $(90 \mathrm{~cm}$ de diâmetro x $100 \mathrm{~cm}$ de profundidade), com água a temperatura de $31 \pm 1{ }^{\circ} \mathrm{C}$. Os ratos realizaram o exercício de natação em grupos de três e no máximo quatro ainda não estarem definidos os mecanismos envolvidos na melhora do perfil lipídico induzida por exercício (Meissner, Havinga, Boverhof, Kema, Groen \& Kuipers, 2010), reforçam a necessidade de novas pesquisas sobre estes aspectos. Nesse sentido, o objetivo do presente estudo foi verificar os efeitos decorrentes do exercício moderado contínuo sobre a contagem total e diferencial de leucócitos, as concentrações de glicose sérica e os teores lipídicos de ratos suplementados e não suplementados com solução carboidratada.

animais por sessão, o que garantiu que os roedores treinassem sem a interferência de outro animal. As cinco semanas restantes foram de exercícios de natação, cinco dias consecutivos por semana e $60 \mathrm{~min}$ contínuos por sessão. $\mathrm{O}$ experimento foi realizado no ciclo claro entre às $12 \mathrm{~h} 00 \mathrm{~min}$ e $15 \mathrm{~h} 00 \mathrm{~min}$. A sobrecarga utilizada foi de $3 \%$ do peso corporal de cada roedor, por ser considerada de intensidade moderada (Kiran, Subramanyam \& Devi, 2004) e abaixo da máxima fase estável de lactato (GOBATTO, Mello, Sibuya, Azevedo, Santos \& Kokubun, 2001). O peso corporal dos animais foi monitorado todos os sábados e feita a correção da sobrecarga a partir da alteração no peso. Os ajustes nas sobrecargas foram realizados considerando somente o peso corporal dos animais, sendo estas cargas corrigidas proporcionalmente ao aumento no peso corporal de cada animal e semanalmente. Os animais dos grupos sedentários foram colocados em tanque com água rasa, em profundidade de $10 \mathrm{~cm}$ (banho de imersão) a temperatura de $31 \pm 1{ }^{\circ} \mathrm{C}$, por $15 \mathrm{~min}$, cinco dias consecutivos por semana e foram usados como controles. Após cada sessão de treinamento de natação, os roedores foram secos e colocados em ambiente com temperatura entre 21 e $25^{\circ} \mathrm{C}$ para evitar complicações fisiológicas provenientes do frio e da umidade. A FIGURA 1 apresenta um resumo do período de adaptação e de treinamento. 


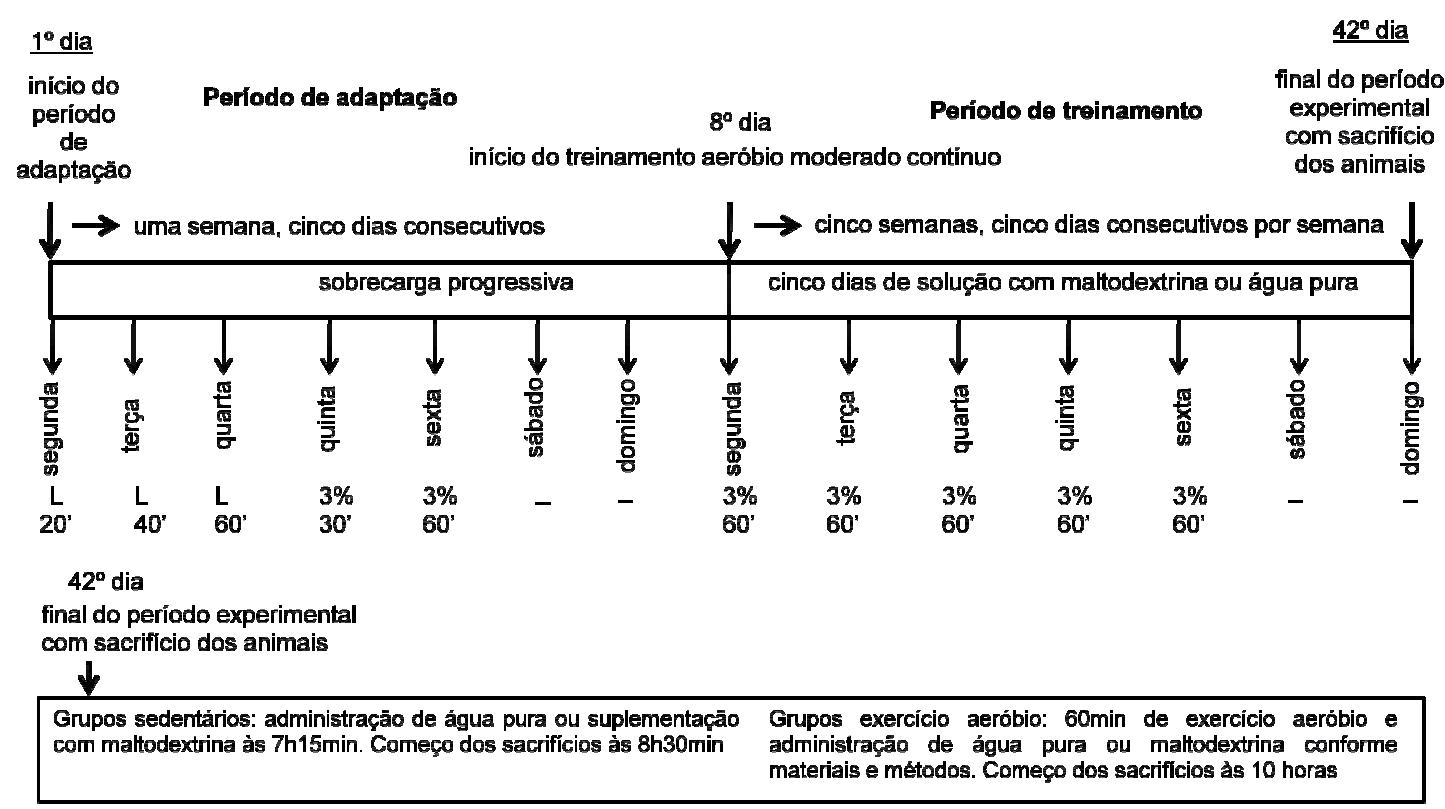

FIGURA 1 - Resumo do período de adaptação e de treinamento.

\section{Protocolo de suplementação}

Os animais suplementados, dos grupos sedentários e treinados, foram suplementados através de tubo gástrico (gavage) com solução carboidratada líquida a $12 \%(\mathrm{~m} / \mathrm{v})$ de maltodextrina (NeoNutri) dissolvida em água destilada (Rombaldi, 1996). Optou-se pela concentração de $12 \%(\mathrm{~m} / \mathrm{v})$ de maltodextrina, pois tanto concentraçōes de 10\% (Rombaldi, 1996; RufFo, 2004), quanto às concentrações de $15 \%$ ou $20 \%$ podem conferir importantes alterações metabólicas (RufFo, 2004). Rombaldi (1996) salienta que concentrações similares a $10 \%$ $(\mathrm{m} / \mathrm{v})$ podem aumentar a performance durante exercício. A dose de carboidrato administrada foi de $0,48 \mathrm{~g} \cdot \mathrm{kg}^{-1}$ de peso, em um volume de $1 \mathrm{ml}$ para $250 \mathrm{~g}$ de peso animal, e a cada $5 \mathrm{~g}$ de peso superior ou inferior ao peso corporal base, o volume aumentou ou diminuiu em $0,02 \mathrm{ml}$. Os animais não suplementados, dos grupos sedentários e treinados, receberam somente água pura utilizando-se a mesma técnica dos grupos suplementados.

Os ratos foram suplementados na última semana de treinamento e por cinco dias para justificar o uso crônico da suplementação com maltodextrina na semana dos sacrifícios. As soluções foram administradas aos animais dos grupos treinados, após os roedores serem submetidos a um aquecimento prévio de natação por $2 \mathrm{~min}$. A escolha deste tempo de aquecimento para posteriores administraçôes das soluções durante as sessões de exercícios de natação foi para que não ocorresse risco de elevação nos níveis de insulina e assim manterem-se elevados os níveis glicêmicos por um maior tempo, conforme sugerem Costill, Bennett, Branam e Eddy (1973), Costill, Coyle, Dalsky, Evans, Fink e Hoopes (1977), Hultman (1989), Horowitz e Coyle (1993), El-Sayed, Rattu e Roberts (1995).

\section{Amostras sanguíneas e análises}

O sacrifício dos animais ocorreu no último dia de treinamento, imediatamente após as sessões de exercício aeróbio, ou após uma hora de repouso depois de efetuadas as administraçôes de água pura ou maltodextrina para os animais dos grupos sedentários, sendo coletadas amostras sanguíneas. As mudanças no número de leucócitos circulantes após sessōes de exercício físico normalmente retornam aos valores de pré-exercício dentro de três a 24 horas, dessa forma, tem se observado durante o período de recuperação, que a função imune parece ser em geral, similar em atletas comparados com os não atletas (GLEESON, 2007). Diante disso, optou-se por realizar os sacrifícios dos animais imediatamente após a última sessão de exercício de natação, com o intuito de se observar o efeito adaptativo e somatório de várias sessões de treinamento sobre a contagem total e diferencial dos leucócitos. Foram obtidos em torno de $1 \mathrm{ml}$ de sangue total com o anticoagulante EDTA para a realização da análise da contagem total e diferencial de leucócitos e outros $4 \mathrm{ml}$ de sangue total sem anticoagulante,
Foram sacrificados cinco animais por grupo, com intervalo de uma semana entre os sacrifícios.

L: livre de sobrecarga. : folga.

3\%: sobrecarga a partir do peso corporal de cada animal. 
que foram imediatamente centrifugados a $3000 \mathrm{rpm}$ por 10 min para obtenção do soro. Alíquotas deste material recém obtido foram estocadas à $-20^{\circ} \mathrm{C}$ para posterior análise das variáveis metabólicas.

\section{Contagem total e diferencial deleucócitos}

Essa análise foi feita de maneira adaptada de Dantas, Ambiel, Cuman, Baroni e Bersani-Amado (2006). A contagem global dos leucócitos foi realizada em câmara de Neubauer, a partir de amostras de sangue diluídas na proporção de 1:20 em líquido de Turk. O material assim obtido foi homogeneizado em agitador magnético durante $45 \mathrm{~s}$ e realizada a contagem total de leucócitos em microscópio Zeiss. A contagem diferencial das células da série leucocitária foi realizada em esfregaços de sangue fixados e corados pelo método de Giemsa. A lâmina foi imersa no corante durante 20 a $30 \mathrm{~min}$. Após, foi retirada, lavada em água corrente e colocada para secar ao ar livre. Foi realizada a contagem diferencial dos leucócitos em microscópio óptico usando-se objetiva de imersão em óleo.

\section{Análises bioquímicas}

As análises séricas de glicose, colesterol total, HDL colesterol, LDL colesterol e triglicérides

\section{Resultados}

\section{Contagem total ediferencial deleucócitos}

Houve uma diminuição significativa $(\mathrm{p}<0,01)$ no número de linfócitos entre os animais treinados em exercício aeróbio contínuo de intensidade moderada e que receberam água, comparado aos ratos sedentários que receberam água pura. Por outro lado, houve um foram feitas por espectrofotometria e seguiram as determinações dos kits comerciais da marca Labtest (Lagoa Santa/MG/Brasil).

\section{Análise estatística}

A análise estatística foi conduzida no pacote estatístico Statistica para Windows, versão 8, da Statsoft. Quando as variáveis seguiram a curva normal foi empregada a análise de variância fatorial para a comparação entre as médias. Quando o F foi significativo, para localizar as diferenças usou-se o teste de Fisher. Para as variáveis que apresentaram comportamento não paramétrico, se utilizou o teste Kruskal-Wallis. Os valores foram expressos como média e desvio-padrão, sendo adotado o nível de significância de $\mathrm{p}<0,05$.

\section{Procedimentos éticos}

Os experimentos com os animais foram realizados de acordo com as resoluções brasileiras específicas sob a Bioética em Experimentos com Animais (Lei no 6638, de 8 de maio de 1979 e Decreto no 24645, de 10 de julho de 1934) e foram aprovados pela Comissão de Ética em Experimentação Animal (CEEA) da UFPel (Processo no 5873/2009). aumento significativo $(\mathrm{p}<0,03)$ no número de linfócitos dos animais treinados em exercício aeróbio contínuo moderado, suplementados com maltodextrina comparado aos animais exercitados aerobicamente e que receberam água pura (FIGURA 2). 


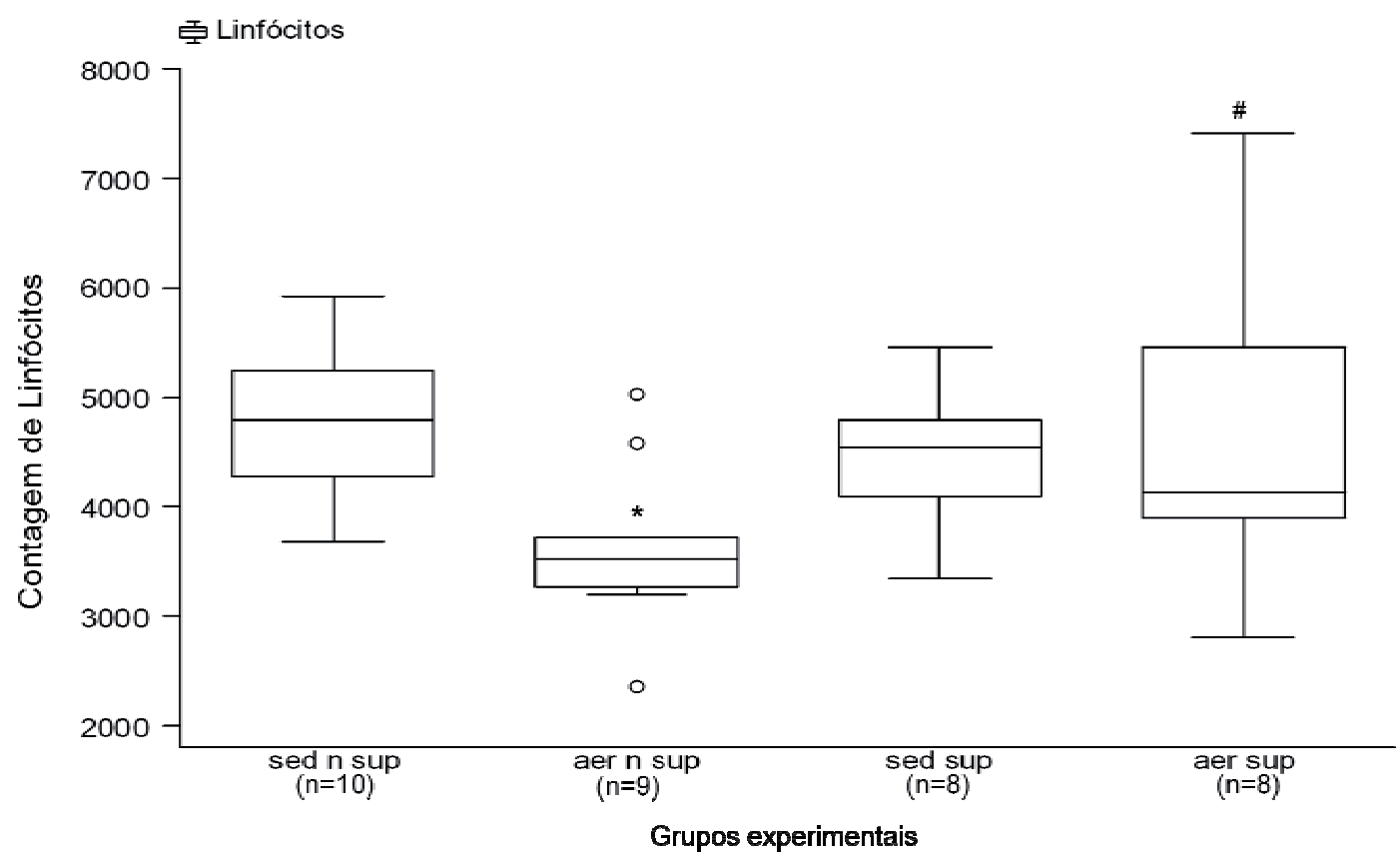

Os valores estão expressos como média e desvio padrão.

"n sup" corresponde aos animais que receberam água pura. "sup" corresponde aos animais suplementados com maltodextrina.

Sed: animais sedentários.

Aer: animais treinados em exercício aeróbio contínuo de intensidade moderada.

${ }^{*} p<0,01$ versus sed n sup.

$\# p<0,03$ versus aer n sup.

Foi utilizado o teste estatístico ANOVA fatorial seguido de Fisher.

FIGURA 2 - Contagem de linfócitos circulantes (no de células/ $\mathrm{mm}^{3}$ ) de ratos Wistar.

Não houve efeito do exercício aeróbio contínuo de intensidade moderada e nem da suplementação com maltodextrina tanto na

contagem total de leucócitos quanto na contagem de neutrófilos, eosinófilos, basófilos e monócitos (TABELA 1).

TABELA 1 - Comparação da contagem total e diferencial deleucócitos entre os grupos experimentais em amostras de sangue total de ratos Wistar.

\begin{tabular}{lcccc}
\hline \multicolumn{3}{c}{ Contagem de leucócitos circulantes $\left(\mathbf{n}^{\circ}\right.$ de células/mm } \\
& \multicolumn{2}{c}{ sed } & aer \\
\cline { 2 - 5 } & $\mathrm{n} \sup (\mathrm{n}=10)$ & $\sup (\mathrm{n}=8)$ & $\mathrm{n} \sup (\mathrm{n}=9)$ & $\sup (\mathrm{n}=8)$ \\
\hline Leucócitos totais & $5700,0 \pm 767,4$ & $5687,5 \pm 787,7$ & $4834,4 \pm 1022,5$ & $5686,3 \pm 1416,3$ \\
Neutrófilos & $673,9 \pm 327,5$ & $995,2 \pm 389,5$ & $918,5 \pm 459,4$ & $786,6 \pm 352,7$ \\
Eosinófilos & $69,1 \pm 40,2$ & $56,9 \pm 7,9$ & $48,3 \pm 10,2$ & $56,9 \pm 14,2$ \\
Basófilos & $57,0 \pm 7,7$ & $56,9 \pm 7,9$ & $48,3 \pm 10,2$ & $56,9 \pm 14,2$ \\
Monócitos & $134,0 \pm 72,7$ & $116,9 \pm 53,1$ & $205,9 \pm 158,5$ & $132,1 \pm 77,2$ \\
\hline
\end{tabular}

\section{Glicemia e perfil lipídico}

\section{Glicose sérica}

Os animais que executaram treinamento aeróbio contínuo de intensidade moderada e que receberam água pura tiveram uma diminuição significativa $(\mathrm{p}<0,001)$ na concentração de glicose sérica comparado ao grupo de animais sedentários que receberam água (FIGURA 3).

\section{Perfil lipídico}

Não houve diferença estatisticamente significativa nas concentrações séricas de colesterol total, HDL colesterol, LDL colesterol e triglicérides entre os diferentes grupos experimentais (TABELA 2).
Os valores estão expressos como média e desvio padrão.

"n sup" corresponde aos animais que receberam água pura. "sup" corresponde aos animais suplementados com maltodextrina.

Sed: animais sedentários.

Aer: animais treinados em exercício aeróbio contínuo de intensidade moderada.

Para todas as variáveis foi utilizado o teste estatístico ANOVA fatorial. 
Os valores estão expressos como média e desvio padrão.

"n sup" corresponde aos animais que receberam água pura. "sup" corresponde aos animais suplementados com maltodextrina.

Sed: animais sedentários.

Aer: animais treinados em exercício aeróbio contínuo de intensidade moderada.

$t p<0,001$ versus sed n sup.

Foi usado o teste estatístico Kruskal Wallis.

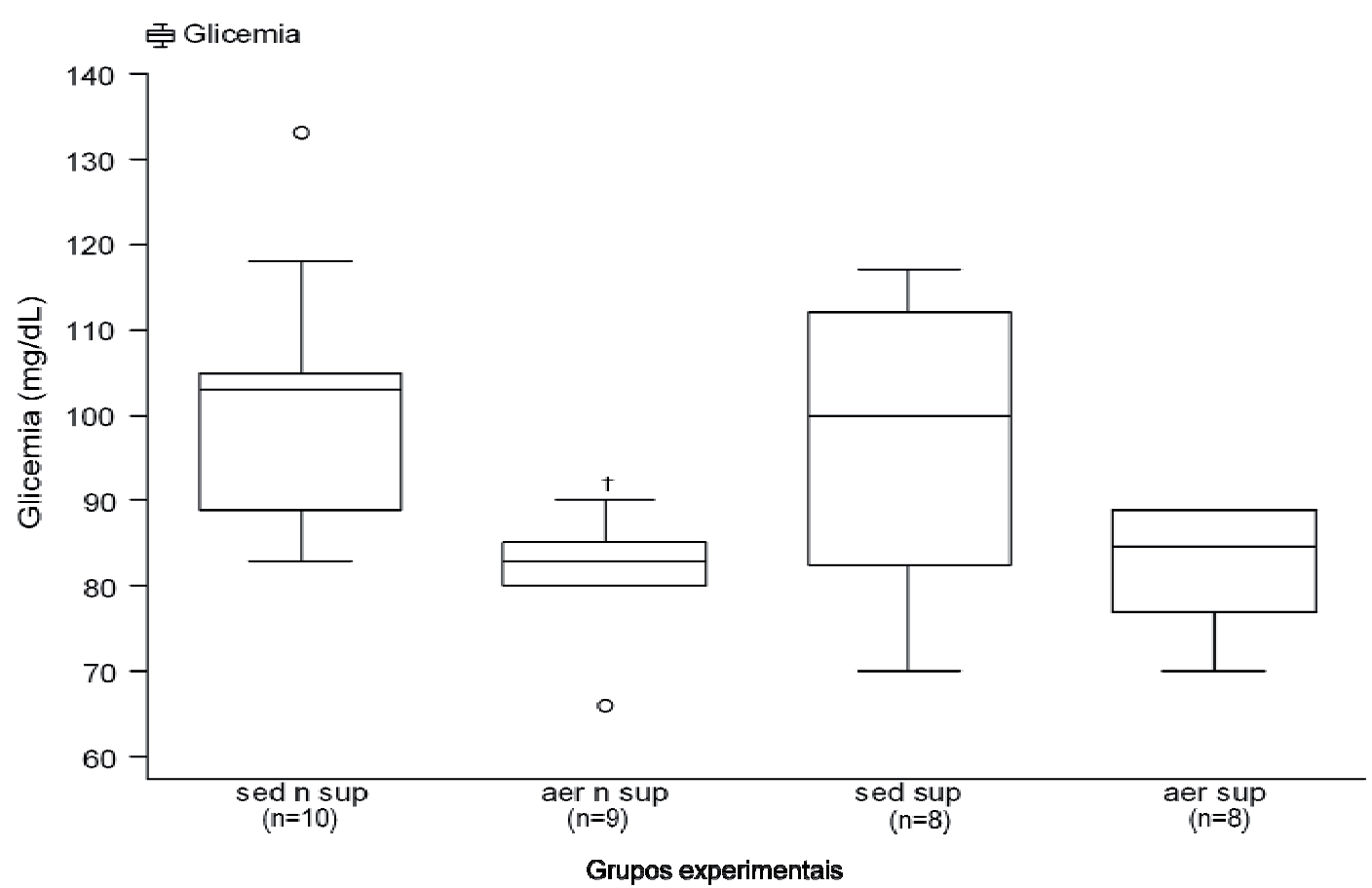

FIGURA 3 - Glicemia (mg/ dL) de ratos Wistar.

TABELA 2 - Efeitos do treinamento aeróbio moderado e de suplementação carboidratada sobre perfil lipídico de ratos Wistar.

\begin{tabular}{|c|c|c|c|c|}
\hline \multirow{2}{*}{ Perfil lipídico } & \multicolumn{2}{|c|}{ sed } & \multicolumn{2}{|c|}{ aer } \\
\hline & $\mathrm{n} \sup (\mathrm{n}=10)$ & $\sup (n=8)$ & $n \sup (n=9)$ & $\sup (n=8)$ \\
\hline $\begin{array}{l}\text { Triglicérides, } \\
(\mathrm{mg} / \mathrm{dL})\end{array}$ & $153,5 \pm 17,2$ & $155,0 \pm 17,4$ & $144,2 \pm 14,7$ & $143,0 \pm 14,5$ \\
\hline $\begin{array}{l}\text { Colesterol total, } \\
(\mathrm{mg} / \mathrm{dL})\end{array}$ & $189,1 \pm 22,3$ & $187,5 \pm 22,8$ & $173,4 \pm 21,8$ & $185,6 \pm 6,7$ \\
\hline $\begin{array}{l}\text { HDL colesterol, } \\
(\mathrm{mg} / \mathrm{dL})\end{array}$ & $59,1 \pm 12,1$ & $60,0 \pm 8,1$ & $66,2 \pm 6,9$ & $62,3 \pm 3,9$ \\
\hline $\begin{array}{l}\text { LDL colesterol, } \\
(\mathrm{mg} / \mathrm{dL})\end{array}$ & $130,0 \pm 32,1$ & $127,5 \pm 25,2$ & $107,2 \pm 22,6$ & $123,4 \pm 4,9$ \\
\hline
\end{tabular}

Os valores estão expressos como média e desvio padrão.

"n sup" corresponde aos animais que receberam água pura. "sup" corresponde aos animais suplementados com maltodextrina.

Sed: animais sedentários.

Aer: animais treinados em exercício aeróbio contínuo de intensidade moderada.

Variável triglicérides foi usado o teste estatístico ANOVA fatorial.

O teste estatístico Kruskal Wallis foi utilizado para as demais variáveis.

\section{Discussão}

O objetivo deste estudo foi verificar os efeitos decorrentes do exercício moderado contínuo sobre a contagem total e diferencial de leucócitos, as concentrações de glicose sérica e os teores lipídicos de ratos suplementados e não suplementados com maltodextrina. Os resultados encontrados neste estudo demonstram que o treinamento aeróbio contínuo de intensidade moderada provoca diminuição na contagem de linfócitos, entretanto, a utilização da solução esportiva contendo maltodextrina atenua a redução no número de linfócitos, embora não tenha ocorrido efeito do treinamento moderado sobre o perfil lipídico.

A maltodextrina é um polímero que normalmente provoca uma alta resposta glicêmica (Wolf, Garleb, Choe, Humphrey \& Maki, 2003), além de ser de fácil absorção intestinal (RUFFo, 2004) e melhor palatabilidade do que soluções esportivas contendo outras fontes de carboidratos (ROMBALDI, 
1996). Os benefícios da suplementação com maltodextrina podem ser explicados principalmente pela manutenção dos altos níveis de glicose sanguínea, evitando provavelmente, um decréscimo no desempenho associado à hipoglicemia (MAMUS, SANTOS, Campbell \& Kreider, 2006).

Do ponto de vista de reposição energética, uma solução esportiva isotônica contendo maltodextrina pode conter cinco vezes mais calorias do que uma suplementação esportiva isotônica contendo glicose (Inagaki, Ishihara, Ishida, Watanabe, Fujiwara, Komatsu, Shirai, Kato, Takanezawa, Furuyashiki, TAKATA \& Seyama, 2011). A utilização da maltodextrina também pode ser explicada pela maior economia nas reservas de glicogênio muscular (LeITE, 2011; Rombaldi, 1996; RUFFo, 2004), maior economia nas reservas de glicogênio hepático (RUFFo, 2004), maiores níveis de glicose sérica e menores níveis de insulina do repouso para o exercício (RombaldI, 1996) em ratos submetidos a exercícios de natação.

A literatura demonstra que o exercício físico pode causar alterações no número de linfócitos circulantes. Em ratos machos Wistar submetidos a sessões agudas de exercícios de baixa e moderada intensidade se detectou um aumento significativo na contagem de linfócitos, comparados ao grupo controle sedentários (Prestes, Ferreira, Dias, Frollini, Donatto, CuryBoaventura, Guereschi, Pithon-Curi, Verlengia, Palanch, Curi \& Cavaglieri, 2008). Após 36 horas do término da sessão de treinamento sob carga de exercício físico para induzir o overtraining em ratos machos Wistar se verificou que a apoptose dos linfócitos foi maior quando comparada ao grupo controle (Dong, Chen, Wang, Yu, Zhang \& XiaO, 2011).

Nesse estudo observou-se que o uso de solução esportiva contendo maltodextrina ocasionou elevação no número de linfócitos no grupo de animais que realizaram exercício aeróbio contínuo, dessa forma o uso de carboidrato contribuiu para atenuar os efeitos do treinamento.

Em humanos os resultados devem ser analisados com cautela. Diferentemente ao presente estudo, Kreider, Earnest, Lundberg, Rasmussen, GreENWOOD, COWAN e ALMADA (2007) não observaram diferença significativa na contagem de linfócitos entre dois grupos de voluntários treinados e suplementados com maltodextrina ou com solução esportiva contendo proteína e sacarose logo após a participação em um programa de treinamento de resistência. NIEMAN, DAvis, Brown, Henson, Dumke, Utter, Vinci, Downs, Smith, Carson, Brown, McAnulty e McAnulty (2004) também notaram que a administração de uma solução carboidratada ( $6 \%$ de carboidrato) a homens treinados e submetidos a sessões de exercícios físicos não modificou a contagem de linfócitos.

Em relação aos teores lipídicos e a glicemia, o presente estudo demonstrou não haver interferência do treinamento contínuo de intensidade moderada e da suplementação com maltodextrina no perfil lipídico, porém, houve um declínio na concentração de glicose sérica.

MeISSNER et al. (2010) ao realizaram um estudo com ratos que correram em roda para corrida voluntária durante duas semanas, observaram que o treinamento aeróbio não ocasionou alteraçōes nas concentraçōes de triglicérides, porém houve uma diminuição significativa nos níveis plasmáticos de colesterol total dos ratos exercitados comparados aos animais mantidos sedentários. Em ratos Wistar machos que realizaram exercício aeróbio de intensidade moderada e foram submetidos à exaustão se identificou que não houve efeito do exercício físico nas concentrações de colesterol total, HDL colesterol e LDL colesterol; por outro lado, o exercício físico proporcionou diminuição na concentração de triglicérides (Pinheiro, Souza Filho, Oliveira Neto, Marinho, Motta Neto, Smith \& Silva, 2009). Ratos Wistar machos foram submetidos a sessóes distintas de exercício aeróbio contínuo ou exercício intermitente durante oito semanas; se observaram que ambos os tipos de exercícios exibiram reduções significativas nas concentrações de triglicérides e aumentos significativos nas concentraçóes de HDL colesterol, entretanto, ambos os padróes de treinamento também apresentaram aumentos nas concentrações de colesterol total (SENE-FiOReSE, Duarte, Scarmagnani, Cheik, Manzoni, Nonaka, Rossi, Duarte \& DÂmaso, 2008).

Em relação à glicemia a literatura demonstra que, em ratos machos Wistar alimentados com dieta normal e submetidos a treinamento de natação com diferentes duraçōes se identificou que a glicemia foi maior nos grupos que nadaram por duas e quatro horas, comparados aos animais do grupo que não se exercitou (Ochiai \& Matsuo, 2009a). Ratos Wistar machos alimentados com dieta rica em carboidratos ou dieta rica em gorduras e cujas coletas sanguíneas foram realizadas pré e pós-exercício de natação se observou que a concentração de glicose sérica não diferiu entre os grupos experimentais no pós-exercício (OchiaI \& MatsuO, 2009b).

As limitações do presente estudo referem-se às necessidades de avaliações dos hormônios 
adrenocorticotrópico, cortisol e insulina relacionados com o metabolismo glicêmico, bem como avaliações de outros marcadores de imunidade, tais como as miocinas. O presente estudo, também, apresenta como limitação a impossibilidade da medida do hormônio adrenalina que tem influência tanto na contagem total e diferencial de leucócitos quanto em demais parâmetros metabólicos.
Em conclusão, este estudo demonstrou que com seis semanas de treinamento aeróbio contínuo de intensidade moderada foi possível identificar alteraçōes no nível glicêmico e no número de linfócitos circulantes, bem como, a interferência positiva de cinco dias de suplementação com maltodextrina na contagem de linfócitos sanguíneos sem, no entanto, causar elevaçōes nos níveis séricos de lipídeos.

\begin{abstract}
Effects of continuous moderate training on immune and metabolic parameters of rats supplemented with maltodextrin

The objective of this study was to determine the effects of continuous moderate exercise on the differential and total count leukocyte, serum glucose concentration and lipid levels of rats supplemented and not supplemented with carbohydrate solution. To this purpose, thirty-five male Wistar rats were divided into four groups: sedentary non-supplemented $(n=10)$ and supplemented $(n=8)$, trained in continuous moderate aerobic exercise non-supplemented $(n=9)$ and supplemented $(n=8)$. The training of continuous swimming was developed during six week with $3 \%$ body weight overload. For five days the animals were supplemented with $0.48 \mathrm{~g} \cdot \mathrm{kg}^{-1}$ maltodextrin daily dose dissolved in water or pure water. Moderate exercise caused a significant decrease in blood glucose $(p<0.001)$ and in the number of blood lymphocytes $(p<$ 0.01 ). Additionally, the maltodextrin significantly increased the number of lymphocytes of trained animals $(p<0.03)$. There was no effect of training and maltodextrin on the lipid profile. The results allowed to conclude that with six weeks of training it was possible to cause a drop in the number of lymphocytes and in the concentration of serum glucose, but with five days of supplementation the decline in the lymphocyte count was attenuated without, however, cause elevations in the lipid profile.
\end{abstract}

UnItERMs: Aerobic capacity; Glucose; Lymphocytes; Carbohydrate.

\title{
Referências
}

ARAÚJO, G.G.; GOBATTO, C.A.; HIRATA, R.D.C.; HIRATA, M.H.; CAVAGLIERI, C.R.; VERLENGIA, R. Respostas fisiológicas para detector o overtraining. Revista da Educação Física/UEM, Maringá, v.19, n.2, p.275-89, 2008. CLOSE, G.L.; ASHTON, T.; CABLE, T.; DORAN, D.; NOYES, C.; McARDLE, F.; MacLAREN, D.P.M. Effects of carbohydrate on delayed onset muscle soreness and reactive oxygen species after contraction induced muscle damage. British Journal of Sports Medicine, London, v.39, n.12, p.948-53, 2005.

COSTILL,D.L.; BENNETT, A.; BRANAM, G.; EDDY, D. Glucose ingestion at rest and during prolonged exercise. Journal of Applied Physiology, Bethesda, v.34, n.6, p.764-9, 1973.

COSTILL, D.L.; COYLE, E.; DALSKY, G.; EVANS, W.; FINK, W.F.; HOOPES, D. Effects of elevated plasma FFA and insulin on muscle glycogen usage during exercise. Journal of Applied Physiology, Bethesda, v.43, n.4, p.695-9, 1977. COX, A.J.; PYNE, D.B.; COX, G.R.; CALLISTER, R.; GLEESON, M. Pre-exercise carbohydrate status influences carbohydratemediated attenuation of post-exercise cytokine responses. International Journal of Sports Medicine, New York, v.29, p.1003-9, 2008. DANTAS, J.A.; AMBIEL, C.R.; CUMAN, R.K.N.; BARONI, S.; BERSANI-AMADO, C.A. Valores de referência de alguns parâmetros fisiológicos de ratos do Biotério Central da Universidade Estadual de Maringá, Estado do Paraná. Acta Scientiarum: Health Sciences, Maringá, v.28, n.2, p.165-70, 2006.

DONG, J.; CHEN, P.; WANG, R.; YU, D.; ZHANG, Y.; XIAO, W. NADPH oxidase: a target for the modulation of the excessive oxidase damage induced by overtraining in rat neutrophils. International Journal of Biological Sciences, Lake Haven, v.7, n.6, p.881-91, 2011. 
EL-SAYED, M.S.; RATTU, A.J.M.; ROBERTS, I. Effects of carbohydrate feeding before and during prolonged exercise on subsequent maximal exercise performance capacity. International Journal of Sports Nutrition, Champaign, v.5, p.215-24, 1995. GLEESON, M. Immune function in sport and exercise. Journal of Applied Physiology, Bethesda, v.103, p.693-9, 2007. GLEESON, M.; NIEMAN, D.C.; PEDERSEN, B.K. Exercise, nutrition and immune function. Journal of Sports Sciences, London, v.22, p.115-25, 2004.

GOBATTO, C.A.; MELLO, M.A.R.; SIBUYA, C.Y.; AZEVEDO, J.R.M.; SANTOS, L.A.; KOKUBUN, E. Maximal lactate steady state in rats submitted to swimming exercise. Comparative Biochemistry and Physiology: Part A: Molecular \& Integrative Physiology, New York, v.130, n.1, p.21-7, 2001.

HOROWITZ, J.F.; COYLE, E.F. Metabolic responses to preexercise meals containing various carbohydrates and fat. American Journal of Clinical Nutrition, Bethesda, v.58, n.2, p.235-41, 1993.

HULTMAN, E. Nutritional effects on work performance. American Journal of Clinical Nutrition, Bethesda, v.49, p.949-57, 1989.

INAGAKI, K.; ISHIHARA, K.; ISHIDA, M.; WATANABE, A.; FUJIWARA, M.; KOMATSU, Y.; SHIRAI, M.; KATO, Y.; TAKANEZAWA, A.; FURUYASHIKI, T.; TAKATA, H.; SEYAMA, Y. Rapid rehydration and moderate plasma glucose elevation by fluid containing enzymatically synthesized glycogen. Journal of Nutritional Science Vitaminology, Tokyo, v.57, n.2, p.170-6, 2011.

KIRAN, T.R.; SUBRAMANYAM, M.V.V.; DEVI, S.A. Swim exercise training and adaptations in the antioxidant defense system of myocardium of old rats: relationship to swim intensity and duration. Comparative Biochemistry and Physiology: Part B: Biochemisty \& Molecular Biology, Oxford, v.137, p.187-96, 2004.

KREIDER, R.B.; EARNEST, C.P.; LUNDBERG, J.; RASMUSSEN, C.; GREENWOOD, M.; COWAN, P.; ALMADA, A.L. Effects of ingesting protein with various forms of carbohydrate following resistance-exercise on substrate availability and markers of anabolism, catabolism, and immunity. Journal of the International Society of Sports Nutrition, Woodland Park, v.4, n.18, p.1-11, 2007.

LEITE, C.F. Dano oxidativo e atividade imunológica de ratos treinados, suplementados com maltodextrina. 2011. 100f. Dissertação (Mestrado em Educação Física) - Escola Superior de Educação Física, Universidade Federal de Pelotas, Pelotas, 2011. MAMUS, R.T.; SANTOS, M.G.; CAMPBELL, B.; KREIDER, R. Biochemical effects of carbohydrate supplementation in a simulated competition of short terrestrial duathlon. Journal of International Society Sports Nutrition, Woodland Park, v.3, n.2, p.6-11, 2006.

MEISSNER, M.; HAVINGA, R.; BOVERHOF, R.; KEMA, I.; GROEN, A.K.; KUIPERS, F. Exercise enhances wholebody cholesterol turnover in mice. Medicine and Science in Sports and Exercise, Madison, v.42, n.8, p.1460-8, 2010. MURPHY, E.A.; DAVIS, J.M.; BROWN, A.S.; CARMICHAEL, M.D.; CARSON, J.A.; VAN ROOIJEN, N.; GHAFFAR, A.; MAYER, E.P. Benefits of oat $\beta$-glucan on respiratory infection following exercise stress: role of lung macrophages. American Journal of Physiology: Regulatory, Integrative and Comparative Physiology, Bethesda, v.294: R1593-R1599, 2008. NATALE, V.M.; BRENNER, I.K.; MOLDOVEANU, A.I.; VASILIOU, P.; SHEK, P.; SHEPHARD, R.J. Effect of three different types of exercise on blood leukocyte count during and following exercise. São Paulo Medical Journal: Revista Paulista de Medicina, São Paulo, v.121, n.1, p.9-14, 2003.

NIEMAN, D.C.; DAVIS, J.M.; BROWN, V.A.; HENSON D.A.; DUMKE, C.L.; UTTER, A.C.; VINCI, D.M.; DOWNS, M.F.; SMITH, J.C.; CARSON, J.; BROWN, A.; McANULTY, S.R.; McANULTY, L.S. Influence of carbohydrate ingestion on immune changes after $2 \mathrm{~h}$ of intensive resistance training. Journal of Applied Physiology, Bethesda, v.96, p.1292-8, 2004.

OCHIAI, M.; MATSUO, T. Prolonged swimming exercise does not affect contents and fatty acids composition of rat muscle triacylglycerol. Journal of Oleo Science, Tokyo, v.58, n.6, p.313-21, 2009a.

. Effects of short-term dietary change from high-carbohydrate diet to high-fat diet on storage, utilization, and fatty acid composition of rat muscle triglyceride during swimming exercise. Journal of Clinical Biochemistry and Nutrition, Mitake, v.44, n.2, p.168-77, 2009b.

PINHEIRO, C.H.J.; SOUZA FILHO, W.M.; OLIVEIRA NETO, J.; MARINHO, M.J.F.; MOTTA NETO, R.; SMITH, M.M.R.L.; SILVA, C.A.B. Exercício físico previne alteraçôes cardiometabólicas induzidas pelo uso crônico de glicocorticóides. Arquivos Brasileiros de Cardiologia, São Paulo, v.93, n.4, p.400-8, 2009.

PRESTES, J.; FERREIRA, C.K.O.; DIAS, R.; FROLLINI, A.B.; DONATTO, F.F.; CURY-BOAVENTURA, M.F; GUERESCHI, M.G., PITHON-CURI, T.C.; VERLENGIA, R.; PALANCH, A.C.; CURI, R.; CAVAGLIERI, C.R. Lymphocyte and cytokines after short periods of exercise. International Journal of Sports Medicine, Stuttgart, v.29, p.1010-4, 2008. 
RADAK, Z.; CHUNG, H.Y.; KOLTAI, E.; TAYLOR, A.W.; GOTO, S. Exercise, oxidative stress and hormesis. Ageing Research Reviews, Oxford,v.7, p.34-42, 2008.

ROMBALDI, A.J. Alguns efeitos bioquímicos da ingestão de carboidrato líquido na realização de trabalho intermitente de alta intensidade em ratos. 1996. 265f. Tese (Doutorado em Ciências do Movimento Humano) - Centro de Educação Física e Desportos, Universidade Federal de Santa Maria, Santa Maria, 1996.

RUFFO, A.M. Efeitos da suplementação de diferentes concentraçóes de maltodextrina em ratos submetidos a exercício contínuo e prolongado. 2004. 78f. Dissertação (Mestrado em Educação Física) - Departamento de Educação Física, Setor de Ciências Biológicas, Universidade Federal do Paraná, Curitiba, 2004.

SENE-FIORESE, M.; DUARTE, F.O.; SCARMAGNANI, F.R.R.; CHEIK, N.C.; MANZONI, M.S.J.; NONAKA, K.O.; ROSSI, E.A.; DUARTE, A.C.G.O.; DÂMASO, A.R. Efficiency of intermittent exercise on adiposity and fatty liver in rats fed with high-fat diet. Obesity, Silver Spring, v.16, p.2217-22, 2008.

WOLACH, B.; GAVRIELI, R.; BEN-DROR, S.G.; ZIGEL, L.; ELIAKIM, A.; FALK, B. Transient decrease of neutrophil chemotaxis following aerobic exercise. Medicine and Science in Sports and Exercise, Madison, v.37, n.6, p.949-54, 2005. WOLF, B.W.; GARLEB, K.A.; CHOE, Y.S.; HUMPHREY, P.M.; MAKI, K.C. Pullulan is a slowly digested carbohydrate in human. Journal of Nutrition, Philadelphia, v.133, n.4, p.1051-5, 2003.

ENDEREÇO Airton J osé Rombaldi Escola Superior de Educação Física Universidade Federal de Pelotas R. Luiz de Camões, 625 96055-630 - Pelotas - RS - BRASIL e-mail: rombaldi@ufpel.tche.br
Recebido para publicação: 05/ 09/2011

Revisado: 31/ 10/2011

Aceito: 06/01/2012 